\title{
Online Bus Reservation System
}

\section{Prof. M. Chavan, Navarange Prajwal, More Vishal, Nagargoje Shubham}

Department of Computer Engineering, MIT Polytechnic, Pune, Maharashtra, India

\begin{abstract}
Article Info

Volume 7, Issue 3

Page Number: 494-496

Publication Issue :

May-June-2021

\section{Article History}

Accepted : 25 May 2021

Published : 31 May 2021

Traveling is a large growing business across all countries. Bus reservation system deals with maintenance of records of details of each passenger. It

also includes maintenance of information like schedule and details of each bus. We observed the working of the Bus reservation system and after going through it, we get to know that there are many operations, which they have to do manually. It takes a lot of time and causing many errors while data entry. Due to this, sometimes a lot of problems occur and they were facing many disputes with customers. To solve the above problem, and further maintaining records of passenger details, seat availability, price per seat, bill generation and other things, we are offering this proposal of computerized reservation system.
\end{abstract}

Keywords: Reservation System, computerized reservation system, DBMS

\section{INTRODUCTION}

The Online Bus Ticket Reservation System is a webbased application that allows visitors check bus ticket availability, buy bus ticket and pay the bus ticket online. This system is established for all the home/office users after gaining access from the administrator. According to Invaderzim.

Online Bus Reservation System provides bus transportation system, a facility to reserved seats, cancellation of seats and different types of enquiry which need an instant and quick reservation. This system can be used by the users in performing online reservation via internet for their all business purposes. Users can use this program directly on their websites and no need to install it.

\section{Motivation :}

The use of bus traveling is a large growing business in India and other countries; hence bus reservation system deals with maintenance of records of each passenger who had reserved a seat for a journey.

It also includes maintenance of information like schedule and details of each bus. Also, we get to know that there are many operations, which they have to do manually. It takes a lot of time and causes many errors. Due to this, sometimes a lot of problems occur and they were facing many disputes with customers. To solve the above problem, and further maintaining records of items, seat availability for customers, price of per seat, bill generation and other things, we are offering this proposal of reservation system. 


\section{Literature Review}

Factors Influencing Online Bus Ticket Booking KEYWORDS: Ticket booking, Online booking, Virtual computing, web services REVIEW OF LITERATURE. Chapter TI is Literature Review and Work Methodology. Customer can buy the bus ticket over the Internet. the online system lets the customers check the The Online Bus Ticket Reservation System is a web-based application that allows, Online Bus Reservation System provides bus transportation system, .. There are more than 30 peer-reviewed academic journals hosted under the 10 Apr 2015 FERSOFT ONLINE BUS TICKET RESERVATION SYSTEM (OBTRS) SRS Reviewed by: . Literature Review Online Billing System Essay.

\section{Problem Statement}

In order to build the system, all the processes in the business should be studied, System study helps us under the problem and needs of the application. System study aims at establishing requests for the system to be acquired, development and installed. It involves studying and analyzing the ways of an organization currently processing the data to produce information. Analyzing the problem thoroughly forms the vital part of the system study. In system analysis, prevailing situation of problem is carefully examined by breaking them into sub problems. Problematic areas are identified and information is collected. Data gathering is essential to any analysis of requests. It is necessary that this analysis familiarizes the designer with objectives, activities and the function of the organization in which the system is to be implemented.

\section{Existing System}

In existing system, there are various problems like keeping records of items, seats available, prices of per/seat and fixing bill generation on each bill. Finding out details regarding any information is very difficult, as the user has to go through all the books manually. Major problem was lack of security.

\section{Proposed System}

The system is very simple in design and to implement. The system requires very low system resources and the system will work in almost all configurations. It has got following features:

Needs a lot of working staff and extra attention on all the records. Ensure data accuracy. Records are efficiently maintained by DBMS.

Advantages And Disadvantages :

Advantages:

1. You can maximize reservations.

Customers who book their own reservations are more likely to show up, making no-shows a thing of the past. If a customer does need to cancel, the spot automatically opens online, giving another customer the chance to book it. By maximizing your reservations, you won't leave unused activity spots or rentals on the table.

2. Quick Payment Methods

With an online booking system, you can require customers to prepay for activities and rentals. This puts money into your pocket faster.

Disadvantages:

1. You Need Internet Access: If you run tours and activities in remote areas where you aren't able to get on the Internet, online booking might not be for you. You'll need reliable Internet access to check your reservations and to add bookings that are made online.

\section{Scope of the work}

The reservation system has three modules. First module helps the customer to enquire the availability 
of seats in a particular bus at particular date, the second module helps him to reserve a ticket and with the third module he can cancel a reserved ticket. The current bus booking system relies on buying tickets from the conductor for commuting to and from a location through public transportation. The task can be tedious if the number of commuters is large.

\section{Conclusion}

Nowadays, bus agencies are taking important role in transportation, and to make reservation reliable they need a strong system that they will make reservation easier, faster and safer. This work designed to meet requirements of a bus reservation system. It has been developed in HTML, PHP, CSS, JAVASCRIPT and database has been built in MySQL. By using this application, the company can provide reservation services and information to their customers without the limitation of office hours or manpower. Not only does it let customers book trips around the clock from any location with an internet connection but it is also designed for use by the company to internally manage their business processes; minimizing human errors and overcoming difficulties and problems that arose in the previous system.

\section{Cite this article as :}

Prof. M. Chavan, Navarange Prajwal, More Vishal, Nagargoje Shubham, "Online Bus Reservation System", International Journal of Scientific Research in Computer Science, Engineering and Information Technology (IJSRCSEIT), ISSN : 2456-3307, Volume 7, Issue 3, pp.494-496, May-June-2021 